\title{
Celulitis submandibular: caso clínico
}

Submandibular cellulitis: report of the clinical case

\section{Resumen}

El tratamiento odontológico moderno y el uso de antibióticos para el tratamiento de las infecciones orales han hecho que las infecciones odontogénicas de cabeza y cuello sean poco frecuentes. Para evitar una obstrucción aguda de la vía aérea, los odontólogos deben ser capaces de reconocer y tratar rápidamente esta condición. Se presenta el caso de un paciente varón de 51 años de edad con una infección profunda de cabeza y cuello causada por la extracción quirúrgica de la tercera molar mandibular derecha. Se discuten las características clínicas, criterios diagnósticos y tratamiento de este tipo de infecciones.

\begin{abstract}
Modern dental care and use of antibiotics for treatment of oral infections have made that head and neck odontogenic infections will be uncommon. To avoid acute airway obstruction, dentists must be able to recognize and treat fastly this condition. Here, we report a clinical case of a male 51 years old patient with a head and neck deep infection caused by surgical removal of the right mandibular third molar. It is showed clinical characteristics, diagnostic criteria and treatment of such infections.
\end{abstract}

\section{Introducción}

Las infecciones de cabeza y cuello se dividen en superficiales y profundas. Las infecciones superficiales usualmente son fáciles de tratar. Las infecciones profundas son difíciles de diagnosticar tempranamente. Las complicaciones que ponen en peligro la vida del paciente (compromiso aéreo, trombosis venosa, compromiso del mediastino, etc.) pueden presentarse por un retraso en el diagnóstico y tratamiento. ${ }^{1,2}$

El origen de la mayoría de infecciones profundas del cuello son infecciones odontogénicas. El espacio submandibular está frecuentemente comprometido en estas infecciones. El espacio submandibular está limitado superiormente por la mucosa oral del piso de boca e inferiormente por la capa superficial de la fascia cervical profunda que se extiende desde la mandíbula hasta el hueso hioides. El músculo milohioideo divide el espacio submandibular en espacio sublingual o espacio superior (que contiene las glándulas sublinguales, la pequeña porción profunda de la glándula submandibular y el conducto de Wharton) y espacio submaxilar o espacio inferior (que contiene la gran porción superficial de la glándula submandibular y sus ganglios linfáticos). Estos espacios se comunican libremente a través del borde posterior del músculo milohioideo. El espacio submaxilar puede ser dividido a su vez en un espacio central submentoniano, entre los vientres anteriores de los músculos digástricos, y los espacios laterales submaxilares. ${ }^{3.5}$

Las infecciones del espacio submandibular pueden también ser consecuencia de sialioadenitis de glándula submandibular, linfadenitis, trauma o cirugía. La angina de Ludwig es una celulitis gangrenosa difusa bilateral que compromete los espacios submaxilar, sublingual y submentoniano, y que recibió su nombre del médico alemán Wilhelm Frederik von Ludwig que fue el primero que la describió. ${ }^{3}$

El origen de la angina de Ludwig es odontogénico en $90 \%$ de los casos. Las infecciones o extracciones recientes de segundas o terceras molares son la etiología más común, debido a que las raíces de esos dientes se extienden por debajo de la línea milohioidea, brindando una vía de extensión hacia el espacio submaxilar. Al progresar el edema la extensión es limitada inferiormente por la capa superficial de la fascia cervical profunda, la cual se extiende entre el hioides y la mandíbula. La celulitis progresa desde el espacio

\section{Víctor Chumpitaz Cerrate'}

\author{
- Departamento Académico de Ciencias \\ Básicas de la Facultad de Odontología de la \\ UNMSM. \\ Correspondencia: \\ Victor Chumpitaz Cerrate \\ Ir. Los Acebos $\mathrm{N}^{\circ}$ 149. Urb. Las Flores de \\ Lima. San Juan de Lurigancho \\ Teléfono: 6197000-3410 \\ Correo electrónico: vchumpitazc@correo. \\ unmsm.edu.pe
}

Palabras Clave: Infección odontogénica, celulitis submandibular, infección de cabeza y cuello.

Key words: Odontogenic infection, submandibular cellulitis, head and neck infection.

submaxilar hacia el espacio sublingual produciendo induración firme del piso de boca, elevación y desplazamiento posterior de la lengua, y compromiso insidioso de la vía aérea., ${ }^{4,-7}$

El objetivo del presente artículo es presentar un caso y revisar las características clínicas, criterios diagnósticos y tratamiento de las infecciones del espacio submandibular.

\section{Reporte del caso}

\section{a) Anamnesis}

Paciente varón de 51 años, sin antecedentes patológicos de importancia, que acudió a la consulta por disfagia, dolor e inflamación hemifacial derecha. El paciente refirió que hace 7 días le realizaron la extracción quirúrgica de la tercera molar mandibular derecha, sin prescripción de antibióticos pre ni postoperatoriamente, y en el postoperatorio le indicaron ketorolaco $10 \mathrm{mg}$ por vía oral, condicional al dolor. Ante la aparición de dolor e inflamación a las pocas horas de finalizada la cirugia, tomó 8 tabletas de ketorolaco entre el primer y segundo día postoperatorio. Ante la persistencia del dolor y la progresión de la inflamación, regresó al lugar donde le realizaron la cirugia, donde le indicaron penicilina clemizol 1000000 UI por vía intramuscular c/24 
horas y naproxeno $550 \mathrm{mg}$ por vía oral c/ 12 horas, ambos durante 5 días. Siguió las indicaciones, pero el dolor y la inflamación continuaron progresando, por lo que luego de 3 días empezó a recibir adicionalmente, por recomendación de un farmacéutico, dicloxacilina 500 mg por vía oral $\mathrm{c} / 6$ horas. El paciente manifestó que en las últimas 24 horas presentó una ligera sensación de opresión en la garganta y una leve dificultad para deglutir los alimentos.

\section{b) Examen clínico}

El paciente fue admitido con presión arterial de $129 / 87 \mathrm{~mm}$ de $\mathrm{Hg}$, frecuencia cardiaca de 81 latidos/minuto, frecuencia respiratoria de 18 respiraciones/minuto y temperatura oral de 38 ${ }^{\circ} \mathrm{C}$. Al examen clínico se observó una tumefacción de consistencia pastosa que comprometia las regiones geniana, preauricular y submandibular derechas y se extendia hacia la región cervical derecha por encima del cartílago tiroides (Fig. 1). La palpación de todas las regiones comprometidas producía un dolor moderado. Intraoralmente se apreciaba el lecho quirúrgico de la tercera molar mandibular derecha en proceso de cicatrización. La palpación de la superficie vestibular del lecho quirúrgico producía un dolor moderado y se apreciaba una ligera secreción purulenta. El paciente no presentaba trismus, ni elevación del piso de boca, ni protrusión de la lengua, ni dificultad para hablar o respirar.

\section{c) Diagnóstico}

Se diagnosticó celulitis de las regiones geniana, preauricular, submandibular y cervical derechas originada por infección del lecho quirúrgico de la tercera molar mandibular derecha.

\section{d) Plan de tratamiento, evolución y} resultados

Se inició terapia antibiótica con clindamicina $600 \mathrm{mg}$ por vía intramuscular $\mathrm{c} / 8$ horas y ciprofloxacino $500 \mathrm{mg}$ por vía oral $c / 12$ horas y terapia antiinflamatoria con dexametasona $4 \mathrm{mg}$ por vía oral c/ 12 horas.

Se controló la evolución clínica luego de dos días de tratamiento, observándose una disminución moderada de la tumefacción en todas las regiones comprometidas (Fig. 2). El paciente refirió que habian desaparecido la sensación de opresión en la garganta y la dificultad para deglutir, y que el dolor en lasregiones comprometidas era leve a moderado. Se decidió continuar la terapia antibiótica. Se suspendió la dexametasona.

Se inició terapia analgésica-antinflamatoria con diclofenaco $50 \mathrm{mg} / 12$ horas paracetamol $500 \mathrm{mg}$ por vía oral c/ 8 horas.

Se realizó otro control de evolución clínica luego de 4 días de tratamiento, donde se observó disminución casi total de la tumefacción de las regiones preauricular, geniana y cervical derechas, persistiendo una ligera tumefacción de la región submandibular derecha. El paciente refirió ausencia de dolor. Se decidió continuar la terapia antibiótica con clindamicina $300 \mathrm{mg}$ por vía oral $c / 6$ horas y ciprofloxacino $500 \mathrm{mg}$ por vía oral c/ 12 horas. Se suspendió la terapia analgésicaantiinflamatoria.
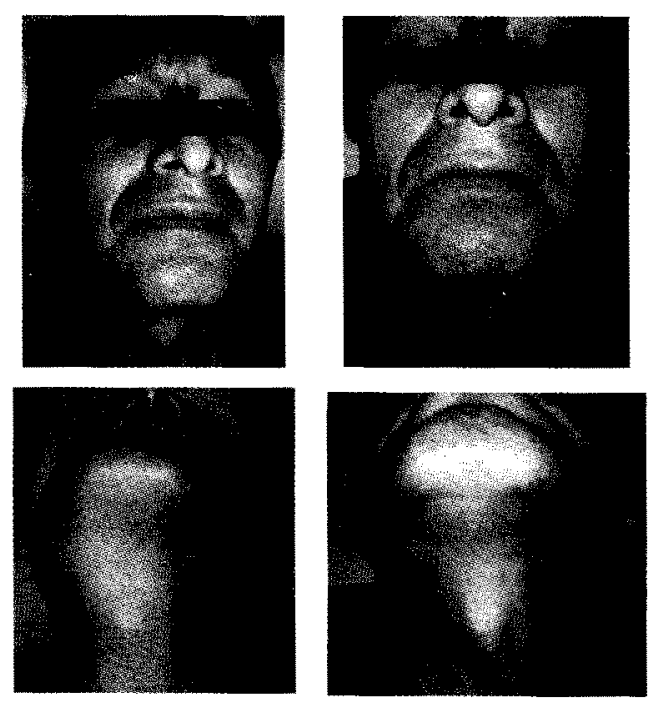

Fig. 1. Imágenes antes del tratamiento.

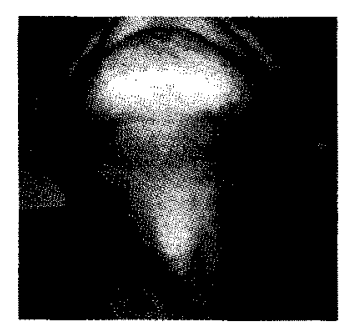

Fig. 2. Imágenes cuatro días Post tratamiento.

Se realizó un nuevo control de evolución clínica luego de 7 días de tratamiento, evidenciándose desaparición completa de la tumefacción de todas las regiones comprometidas inicialmente. Se observó el lecho quirúrgico de la tercera molar mandibular derecha con cicatrización completa, sin dolor ni secreciones a la palpación.

Se decidió continuar la terapia antibiótica por 2 días más.

Luego de 9 dias de tratamiento se realizó un control final, comprobándose la ausencia absoluta de signos y sintomas de infección e inflamación (Fig. 3), por lo que el paciente fue dado de alta sin prescripción adicional.

\section{Discusión}

De las infecciones profundas de cabeza y cuello, la angina de Ludwig representa $37 \%$ de casos, la infección del espacio submandibular $27 \%$, la infección del espacio masticatorio $13 \%$, los abscesos parafaríngeos $11 \%$, los abscesos del espacio parotideo $6 \%$, los abscesos retrofaríngeos $5 \%$ y los abscesos prevertebrales $1 \%$. Es importante reconocer oportunamente los signos y sintomas característicos de estas infecciones, en especial de las más prevalentes, como la angina de Ludwig y la infección del espacio submandibular.

Los signos y sintomas más relacionados con infecciones profundas de cabeza y cuello son fiebre $(82 \%)$, inflamación del cuello $(68 \%)$, trismus $(51 \%)$, inflamación facial $(45 \%)$, eritema cutáneo $(45 \%)$, disfagia $(26 \%)$, dolor dentario $(22 \%)$ y estridor (9\%). ${ }^{1}$ En el presente caso se confirmó la presencia de fiebre, inflamación facial y del cuello, y disfagia. Estos hallazgos indicaron claramente que la infección.estaba progresando hacia planos profundos de cabeza y cuello y que requería tratamiento inmediato.

Las infecciones del espacio submandibular que pueden progresar a angina de Ludwig, han sido reportadas, en muchos casos, originadas por una infección de premolares y molares mandibulares o por extracciones recientes de segundas y terceras molares mandibulares. 4,8 Coincidentemente con la literatura, en nuestro paciente el origen del proceso infeccioso fue la extracción reciente de la tercera molar mandibular derecha.

Muchos pacientes con celulitis no requieren hospitalización y pueden tratarse ambulatoriamente. Las potenciales desventajas de la hospitalización incluyen costos relativamente altos y exposición a infecciones nosocomiales. Entre los pacientes con celulitis moderada a severa, la mayoría requiere antibióticos por vía parenteral por un 
tiempo corto. Se ha demostrado que es posible tratar la celulitis moderada a severa en pacientes adultos de forma ambulatoria. ${ }^{9}$ Debido a las características clínicas del proceso infeccioso al momento de admitir a nuestro paciente, se consideró que éste podía ser tratado ambulatoriamente con antibióticos parenterales y controlando estrictamente la evolución clínica del proceso.

Las infecciones profundas del cuello son generalmente polimicrobianas, incluyendo aerobios y anaerobios. Como consecuencia la terapia antibiótica empirica debe dirigirse contra patógenos aerobios y anaerobios. Las bacterias anaeróbicas más aisladas fueron Prevotella, Porphyromona, Fusobncterium y Peptostreptococcus spp. y las bacterias aeróbicas más aisladas fueron Streptococcus del grupo A, Streptococcus viridans, Staphylococcus aureus y Haemophilus influenzae. Más de dos tercios de las infecciones contienen bacterias productoras de betalactamasa. ${ }^{3}$ Otros reportes manifiestan que los patógenos más frecuentemente asociados con celulitis moderadas a severas son Staphylococcus aureus y Streptococcus beta hemolítico del grupo A (S. pyogenes).

Los microorganismos más aislados de angina de Ludwig fueron Streptococcus spp. en $40 \%$ de pacientes. Los bacilos gramnegativos (entre ellos Pseudonona nertuginosa, Haemophilus influenzae, Branhnmella) fueron aislados en $25 \%$ de pacientes, y los anaerobios (entre ellos Bacteroides) en $20 \%$ de pacientes. El rol de los anaerobios puede estar subestimado debido a dificultades propias de su cultivo. ${ }^{4}$ Según otros estudios, los patógenos más comunes son Streptococcus viridans y Escherichin coli. $^{8}$

Los tratamientos antibióticos más empleados para angina de Ludwig fueron la asociación penicilina $G$ cristalina con clindamicina en $63,6 \%$ de pacientes; penicilina-clindamicinaamikacina en $9,9 \%$ de pacientes; ceftazidima-clindamicina en $8,2 \%$ de pacientes. Otros esquemas antibióticos fueron ceftriaxona-clindamicina; ceftazidima-clindamicina-amikacina, ciprofloxacino-clindamicina, teicoplanina-ciprofloxacino-clindamicina. ${ }^{10}$ En los pacientes que no respondieron efectivamente a la asociación penicilina G con clindamicina, el tratamiento fue cambiado a ciprofloxacino asociado con clindamicina obteniéndose una buena respuesta. ${ }^{10} \mathrm{La}$ piedra angular del tratamiento es un antibiótico acti- vo contra estreptococos, estafilococos y anaerobios. Se sugiere terapia con esteroides para detener la progresión del edema y evitar la necesidad de una vía aérea artificial. ${ }^{4}$ Según estas consideraciones, se inició el tratamiento del paciente con clindamicina $600 \mathrm{mg}$ por via intramuscular $c / 8$ horas asociada a ciprofloxacino $500 \mathrm{mg}$ por vía oral c/ 12 horas, y dexametasona $4 \mathrm{mg}$ por vía oral c/ 12 horas.

Es común no observar mejoría clínica significativa en las primeras 24 horas de tratamiento. Incluso a las 48 horas de iniciado el tratamiento, el $50 \%$ de pacientes permanecen significativamente sintomáticos. En promedio se requieren 2 dias de terapia antibiótica por vía parenteral para lograr reducir $75 \%$ o más el tamaño de la celulitis. Se recomienda lograr una reducción de $75 \%$ o más en el tamaño de la celulitis antes de detener la terapia antibiótica por vía parenteral y continuar por vía oral. ${ }^{9}$ Los hallazgos coinciden parcialmente con la literatura, ya que luego de 2 días de tratamiento, se observó que el tamaño de la celulitis del paciente disminuyó $40 \%$; y luego de 4 días de tratamiento, el tamaño de la celulitis disminuyó $80 \%$. Por lo tanto, luego de 4 días de tratamiento, se decidió continuar la terapia antibiótica con ambos fármacos por vía oral.

La infección generalmente responde a antibióticos parenterales, por 10 que la incisión y el drenaje deben ser pospuestos el mayor tiempo posible debido a que las grandes colecciones de pus son raras. ${ }^{8}$ La intervención quirúrgica se reserva para infecciones que forman una colección localizada de absceso y en quienes no hay respuesta a una terapia adecuada. ${ }^{4}$ El drenaje quirúrgico está indicado para un paciente con complicaciones inminentes y si no ha habido ninguna mejoría después de 24 a 48 horas de antibióticos parenterales. ${ }^{10}$ En el caso del paciente no se presentó ninguno de esos cuadros, no se formó una colección de pus en ningún momento $y^{*}$ si se observó una mejoría evidente desde las 48 horas de iniciado el tratamiento, por lo tanto el paciente no necesitó ningún tipo de drenaje quirúrgico.

\section{Conclusiones}

Los cuadros de celulitis odontogénica moderada a severa en pacientes adultos, pueden tratarse ambulatoriamente con antibióticos parenterales y controlando estrictamente la evolución clínica.
Los antibióticos de elección part pacientes adultos con celulitis odontogénica moderada a severa deben ser activos contra estreptococos, estafilococos, anaerobios y además deben ser preferentemente resistentes a betalactamasas.

La terapia antibiótica parenteral en pacientes adultos con celulitis odontogénica moderada a severa puede continuarse por la vía oral, luego de haber conseguido una reducción de 75 a $80 \%$ en el tamaño de la celulitis.

\section{Referencias bibliográficas}

1. Larawin V, Naipaol, DubeisP. Head and neck space infections. Otolaryngology Head and Neck Surgery 2006;135:889-93.

2. ReynoldsSC, Chow AW. Life-threatening infections of the peripharyngeal and deep fascial spaces of the head and neck. Infect Dis Clin North Am 2007;21:55776.

3. Boscolo-Rizzo P, Da Mosto MC. Submandibular space infection: a potentially lethal infection. International Journal of Infectious Diseases 2009;13:327-33.

4. Britt JC, Josephson GD, Gross CW. Ludwig's angina in the pediatric population: report of a case and review of the literature. International Journal of Pediatric Otorhinolaryngology 2000;52:79-87.

5. Boscolo-Rizzo P, Marchiori C, Montolli F, Vaglia A, Da Mosto MC. Deep neck infections: a constant challenge. J Otorhinolaryngol Relat Spec 2006:68:259-65.

6. Spitalnic S], Sucov A. Ludwig's angina: case report and review. The Journal of emergency Medicine 1995;13(4):499 503.

7. Gaspari RJ. Bedside ultrasound of the soft tissue of the face: a case of early Ludwig's angina. The Journal of emergency Medicine 2006;31(3):287-291.

8. Friedrichs I, Rowe-Jones J. Acute and chronic infections of the ear, nose and throat. Surgery 2004;22(8):178-181.

9. Gouin S, Chevalier I, Gauthier M, Lamarre V. Prospective evaluation of the management of moderate to severe cellulitis with parenteral antibiotics at a paediatric day treatment centre. Journal of Paediatric and Child Health 2008;44:214-18

10. Bross-Soriano D, Arrieta-Gómez J, Prado-Calleros H, Schimelmitz-Idi J. Management of Ludwig's angina with small necks incisions: 18 years experience. Otolaryngology - Head and Neck Surgery 2004;130(6):712-

Fecha de recepción: 13 abril 2009

Fecha de aceptacion: 10 julio 2009 